International Conference on Geotechnical Engineering for Disaster Mitigation \& Rehabilitation Chu, Phoon \& Yong (eds) (c) 2005 World Scientific Publishing Company ISBN 981-256-469-1

\title{
ZONING FOR LIQUEFACTION AND ACTUAL DAMAGE DURING THE 2005 FUKUOKAKEN-SEIHO-OKI EARTHQUAKE
}

\author{
HIDEO NAGASE \\ Kyushu Institute of Technology, 1-1 Sensui, Tobata-ku, Kitakyushu, 804-8550, Japan \\ AKIHIKO HIRO-OKA \\ Kyushu Institute of Technology, 1-1 Sensui, Tobata-ku, Kitakyushu, 804-8550, Japan \\ NORIYUKI YASUFUKU \\ Kyushu University, 6-10-1 Hakozaki, Higashi-ku, Fukuoka, 812-8581, Japan \\ KOUZOU HIRAMATSU \\ WESCO Co., Ltd., 2-5-35 Shimadahonmachi, Okayama, 700-0033, Japan \\ KENJI HASHIMURA \\ Nihon Chiken Co., Ltd., 5-25-25 Moro-oka, Hakata-ku, Fukuoka, 816-0094, Japan
}

On March 20, 2005, an earthquake of magnitude 7.0, which was named as the 2005 Fukuokaken-seiho-oki earthquake, occurred at the northwest part of Fukuoka City. During the earthquake, liquefaction took place mainly in the reclaimed lands of the Hakata Bay area and caused structural damage. In this paper, the distribution of the sites where liquefaction occurred and the characteristics of the grain size of sand boils collected at the sites were clarified. Further, the occurrence of liquefaction in the reclaimed land was discussed with reference to some instances, and the structural damage was summarized. Furthermore, liquefaction analysis was performed using a program called "SHAKE," and several soil profiles of the reclaimed land and alluvial ground in order to investigate the relationship between the occurrence of liquefaction and the distribution of acceleration, which was estimated from earthquake response analyses and the mechanical and physical properties of the soils.

\section{DISTRIBUTION OF SITES WHERE LIQUEFACTION OCCURRED}

In the survey performed immediately after the earthquake, the occurrence of liquefaction was evident by the existence of sand boils on the ground surface. Figure 1 indicates the distribution of the sites where liquefaction occurred in the Hakata Bay area. It can be seen from this figure that the sites that exhibited liquefaction were distributed mainly in the reclaimed lands of the Hakata Bay area and were studded with reclaimed lands. Therefore, the degree of severity of liquefaction due to the earthquake is not regarded to be high as compared with that observed in past earthquakes, for example, the 2000 Tottoriken-seibu earthquake. On the contrary, the occurrence of liquefaction in alluvial ground was nearly negligible. It may be considered that the occurrence of liquefaction is related to the 
characteristics of earthquake motion and the magnitude of the liquefaction strength of soil. The grain size distribution curves of sand boils observed in several reclaimed lands in the Hakata Bay area were investigated. The particle size $\mathrm{D}_{50}$ is $0.15-1.06 \mathrm{~mm}$ and the uniformity coefficient Uc is 1.7-7.1. The boiled sand is classified as a relatively well graded middle sand to poorly graded fine sand, provided certain sand samples are excluded from the sand boils.

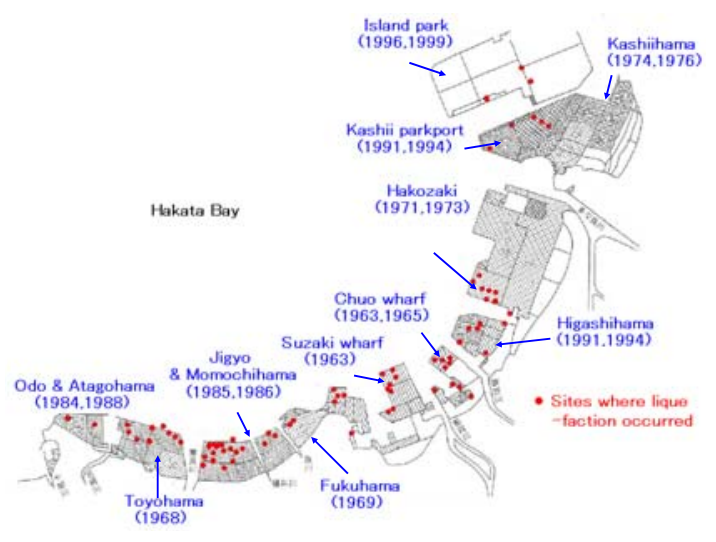

Figure 1. Distribution of sites where liquefaction occurred in reclaimed lands of Hakata Bay area

\section{OCCURRENCE OF LIQUEFACTION IN RECLAIMED LANDS}

With regard to the occurrence of liquefaction in the reclaimed lands, the following features are evident upon investigating the reclamation method and properties of the soil used for the reclamation.

1) In general, it is more difficult for liquefaction to occur if the duration of sedimentation is long. However, the trend of liquefaction resistance is not observed because several types of soils and methods of reclamation were used in the construction of the reclaimed lands.

2) In the east side of the reclaimed lands, for example, in Hakozaki wharf, dredged soil composed of sand, silt, and clay, which was supplied from the sea bed of Hakata Bay, was reclaimed by a pumping method, and the fine content and clay content of the sediment soil are variable in the reclaimed land. Therefore, it can be considered that the sites where liquefaction occurred during the earthquake were especially studded with reclaimed lands.

3) In Island Park City, most of the land was not liquefied because dredged soil with a high proportion of fine content was used for the reclamation. However, a section of the temporary embankment of the sea wall and the backfilled ground of the quay wall were liquefied because clean sand with a small proportion of fine content was used for reclamation in these places. This phenomenon was observed in the western parts of the reclaimed lands, such as Momochihama and Atagohama.

\section{STRUCTURAL DAMAGE DUE TO LIQUEFACTION}

During the earthquake, shore structures and roads were damaged to a large extent due to liquefaction. In addition, a huge flow phenomenon occurred due to liquefaction in the gently sloping ground in a park. In this chapter, the typical damage incurred by quay wall structures and the flow failure of sloping ground are introduced. 


\section{Damages to quay walls}

In Tyuou wharf, a quay wall moved around $1 \mathrm{~m}$ toward the sea and the backfilled ground sank by around $1.2 \mathrm{~m}$. This represents the maximum extent of the damage to the quay walls. Several sand boils were observed on the surface of the backfilled ground. This quay wall is of an L-shaped concrete block type. In the groin portion of the Tyuou wharf area, the L-shaped type quay wall also moved into the sea by around $20 \mathrm{~cm}$ and several cave-ins occurred in the ground surface of the groin. In Hakozaki wharf, the difference between the levels of the quay wall and the backfilled ground was observed to be 30-50 $\mathrm{cm}$. The quay wall is an auxiliary sheet pile type.

\section{Flow failure of sloping ground}

At the Uminonakamichi Seaside Park, flow failure occurred in an open space with a gently sloping ground toward a pond named as "Kamo-ike." Photo 1 shows the state of the flow failure immediately after the earthquake, and Figure 2 indicates the locations at which the survey was carried out for measuring the ground displacement. Figure 3 indicates the relationship between the ground displacement due to flow failure

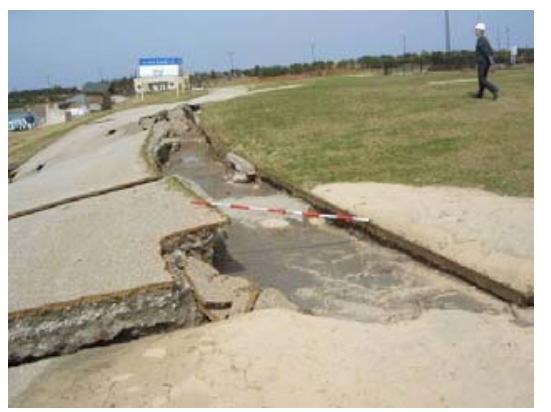

Photo 1. Flow failure of the ground at the Uminonakamichi Seaside Park and its distance from the waterline of the pond. It can be seen from the figure that the ground displacement reached a maximum of around $10 \mathrm{~m}$, although the maximum displacement in the c-c line was around $1 \mathrm{~m}$. It appears that a stone stairway that was constructed near the waterline had a restraining effect on the ground displacement. Furthermore, a worker who manages tourist boats was interviewed regarding the flow phenomenon. It was clarified from this interview that the flow failure occurred almost immediately after the occurrence of liquefaction during the earthquake.

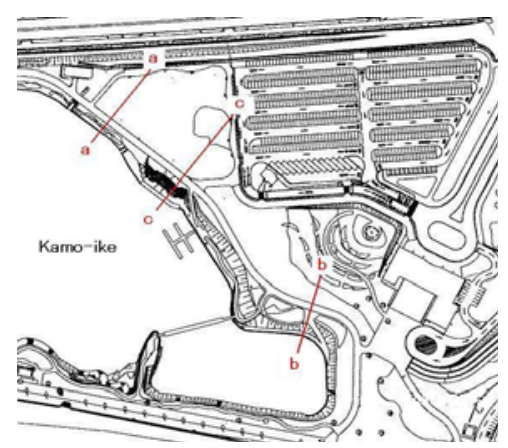

Figure 2. Locations at which the survey of ground displacement due to flow failure was carried out

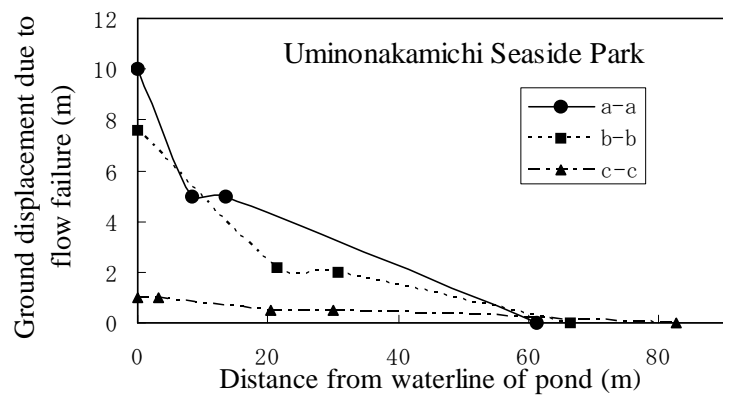

Figure 3. Relationship between ground displacement due to flow failure and distance from the waterline of the pond 


\section{ANALYTICAL INVESTIGATION}

\section{Analytical procedure}

The sites where liquefaction occurred during the earthquake were almost restricted to the reclaimed lands. In order to clarify the reason for this peculiarity in the liquefaction phenomenon, a liquefaction analysis was performed for the reclaimed land and alluvial

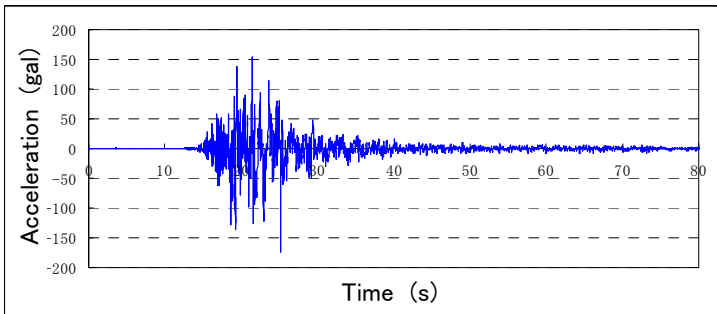

Figure 4. Wave form used for one dimensional seismic response analysis ground. The method of the liquefaction analysis is explained as follows;

1) A program for one dimensional seismic response analysis, "SHAKE," was used to obtain the accelerations on the ground surface.

2) The seismic waveform for the analysis is obtained from a modification involving a conversion of the seismic record of the EW component measured on the ground surface at Fukuoka public hall into that for the basement layer using the "SHAKE" program. Figure 4 shows the seismic waveform for the analysis. The maximum acceleration is 174.911 gal.

3) The shear wave velocity was obtained from the following empirical formulae;

$$
\mathrm{Vs}=157 \mathrm{~N}^{0.180} \text { for clayey soil } \quad \mathrm{Vs}=144 \mathrm{~N}^{0.159} \text { for sandy soil }
$$

4) The strain dependencies of the dynamic shear modulus ratio $G / G_{0}$ and damping constant h were expressed by empirical formulae proposed by Yasuda et al. (1985).

5) The soil boring logs used in the analysis are shown in Figure 5.

6) The shear stress ratio during the earthquake, L, was calculated by the following equation;

$$
\mathrm{L}=(1-0.015 \mathrm{Z}) \cdot \mathrm{k}_{\mathrm{hc}} \cdot \sigma_{\mathrm{v}} / \sigma_{\mathrm{v}}{ }^{\prime}
$$

$\mathrm{Z}$ and $\mathrm{k}_{\mathrm{hc}}$ denote the depth from the ground surface and the ratio of the maximum acceleration on the ground surface to the gravity acceleration, respectively. $\sigma_{\mathrm{v}}$ and $\sigma_{\mathrm{v}}{ }^{\prime}$ denote the vertical total and effective stress, respectively.

7) The liquefaction strength ratio $R$ was calculated from two sets of equations, Methods 1 and 2, as shown in Table 1. These methods were referred to the Japanese certifications for highway bridges given in Japan Road Association (1996, 1990). In Method 2, the value of 0.187 was added to the liquefaction strength ratio $\mathrm{R}$, on the basis of the results of Yasuda et al. (1991). This indicates that the modification for the value of $\mathrm{N}$ is generally underestimated because alluvial soil contains a relatively higher proportion of fine content. Using these methods, the liquefaction ratio was obtained for the following three cases;

Case 1: Method 1 was used; the fine content ratio Fc of the silty or clayey sand and silt in the alluvial soil layer were $30 \%$ and $60 \%$, respectively. 
Case 2: Method 1 was used; the Fc value was $40 \%$ and $80 \%$, in the same manner as in Case 1.

Case 3: Method 2 was used; the $D_{50}$ value of the sandy soil in the alluvial soil layer was $0.35 \mathrm{~mm}$.

8) The ratio of $F_{L}-$ a safety factor against liquefaction—was obtained from the following equation.

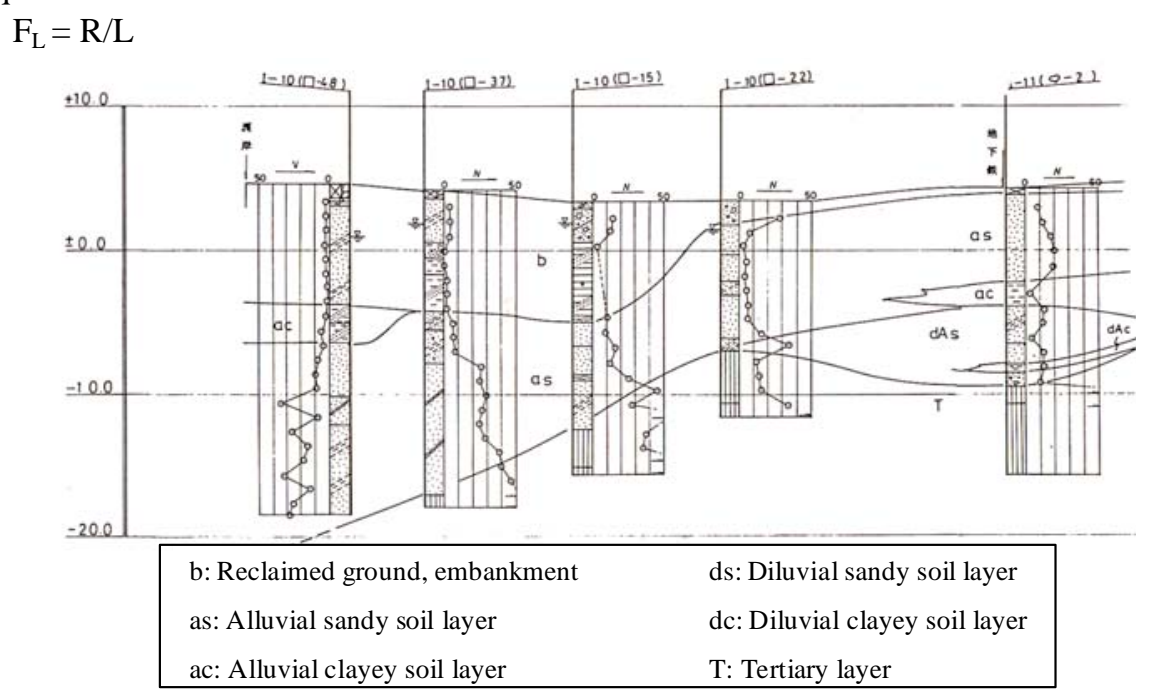

Figure 5. Soil boring logs for liquefaction analysis

Table 1. Explanation of two sets of liquefaction strength ratios

\begin{tabular}{|c|c|c|}
\hline \multicolumn{2}{|l|}{ Method 1} & Method 2 \\
\hline \multicolumn{2}{|l|}{$\left(N_{a}<14\right)$} & $\left(0.02 \mathrm{~mm} \leq D_{50} \leq 0.05 \mathrm{~mm}\right)$ \\
\hline$\left(N_{a} \geq 14\right)$ & & $\begin{array}{l}R=0.0882 \sqrt{\frac{N}{\sigma_{v}^{\prime}+0.7}}+0.19+0.187 \\
(0.05 \mathrm{~mm} \leq D \leq 0.6 \mathrm{~mm})\end{array}$ \\
\hline \multicolumn{2}{|c|}{$R=0.0882 \sqrt{\frac{N_{a}}{1.7}}+1.6 \times 10^{-6}\left(N_{a}-14\right)^{4.5}$} & $R=0.0882 \sqrt{\frac{N}{\sigma_{v}^{\prime}+0.7}}+0.225 \log _{10}\left(\frac{0.35}{D_{50}}\right)+0.187$ \\
\hline \multicolumn{2}{|c|}{$N_{a}=c_{1} N_{1}+c_{2}$} & $\left(0.6 \mathrm{~mm} \leq D_{50} \leq 2.0 \mathrm{~mm}\right)$ \\
\hline$N_{1}=\frac{1.7 N}{\sigma_{*}^{\prime}+0.7}$ & & $R=0.0882 \sqrt{\frac{N}{\sigma^{\prime}+07}}-0.05+0.187$ \\
\hline 1 & $\left(0 \% \leq F_{c}<10 \%\right)$ & \\
\hline$c_{1}=\left\{\left(F_{c}+40\right) / 50\right.$ & $\left(10 \% \leq F_{c}<60 \%\right)$ & \\
\hline$F_{c} / 20-1$ & $\left(60 \% \leq F_{c}\right)$ & \\
\hline$-\int 0$ & $\left(0 \% \leq F_{c}<10 \%\right)$ & \\
\hline$c_{2}=\left\{\left(F_{c}-10\right) / 18\right.$ & $\left(10 \% \leq F_{c}\right)$ & \\
\hline
\end{tabular}

\section{Results of the analysis}

Figure 6 shows the results of the liquefaction analysis for Cases 1 to 3 . The $F_{L}$-value for the reclaimed land is lesser than 1.0; this implies that liquefaction occurs in the reclaimed land in Cases 1 to 3, except for (c). However, in the alluvial soil layer, liquefaction occurs apparently in (a), (c), and (d) in Case 1; does not occur in (a) and (c); and its occurrence seems unlikely in (d) in Case 2. On the contrary, liquefaction does not occur in the 
alluvial soil layer in Case 3. It is evident that the result of the prediction of the occurrence of liquefaction depends on the manner in which the liquefaction strength is modified using the fine content ratio. And, it may also be considered for Cases 1 and 2 that the effect of fine content on the liquefaction strength was not properly accounted for in the analysis. It is noteworthy that the occurrence of liquefaction was suitably predicted in Case 3, although other predictions in this case would be necessary in this regard to confirm the accuracy of the analysis.

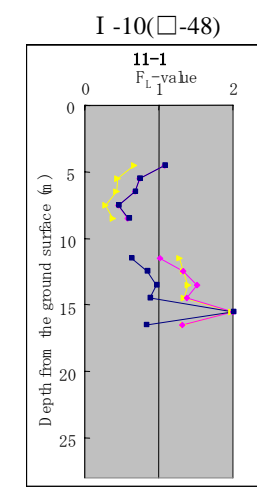

(a)

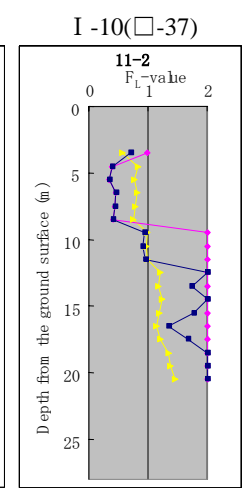

(b)

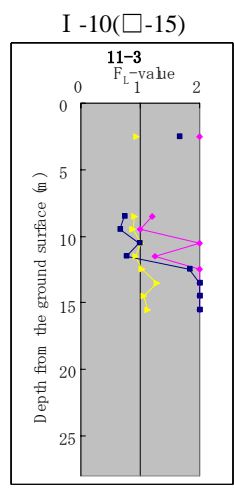

(c)

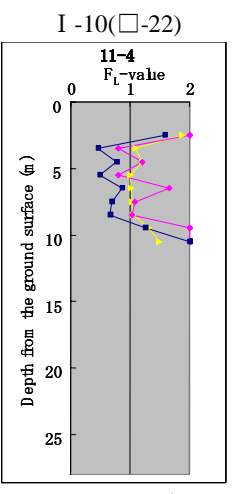

(d)

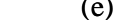

Figure 6. Results of liquefaction analysis

\section{CONCLUSIONS}

The 2005 Fukuokaken-seihou-oki earthquake in Fukuoka City was unexpected. During the earthquake, liquefaction occurred in the reclaimed lands of the Hakata Bay area and caused structural damage, although the magnitude of the earthquake was not significantly large. In this paper, the special features of liquefaction phenomena were summarized, and the results of liquefaction analysis were discussed in order to examine the susceptibility of the reclaimed lands of the city to the liquefaction phenomenon.

\section{REFERENCES}

Yasuda, S. and Yamaguchi, I. (1985): " Dynamic soil properties of undisturbed samples," Proc. of the 20th Japan National Conference on Soil Mechanics and Foundation Engineering, pp.539-542 (in Japanese).

Yasuda, S. and Matsumura, S. (1991): "Microzonation for liquefaction slope failure and ground response during earthquake in Fukuoka City," Proc. of the 4th International Conference on Seismic Zonation, Vol.3, pp.703-724.

Japan Road Association (1990): " Specification for highway bridges," Part 5 Earthquake Resistant design (in Japanese).

Japan Road Association (1996): " Specification for highway bridges," Part 5 Earthquake Resistant design (in Japanese). 